\title{
Effect of vascular endothelial growth factor gene polymorphisms on disease activity in rheumatoid arthritis
}

\author{
Rehab A. Sallam ${ }^{1 *}$, Bassant S. Saad ${ }^{1}$, Mona A. El Wassefy ${ }^{2}$ and Basma A. EL Kady ${ }^{1}$
}

\begin{abstract}
Background: The full etiology of RA remains unclear; in addition to the contributions of infectious, hormonal, and environmental factors, several lines of evidence have suggested that the disease has a genetic basis. The VEGF gene is also an independent risk factor for RA severity and correlates with multiple disease parameters, such as disease activity, joint damage, and functional disability. This case-control study aimed to investigate the impact of a common genetic polymorphism in the vascular endothelial growth factor (VEGF) gene on disease activity and synovial lesions in patients with rheumatoid arthritis (RA).

Results: T allele was present in the RA group more frequently ( $22.5 \%$ vs. $10 \%$ respectively in controls). The $\mathrm{C}$ allele was less frequent in the RA group (77.7\% vs. $90 \%$ respectively in controls) $(P=0.002)$. Homozygous genotype (CC) was found in $61.2 \%$ of patients and $82.5 \%$ of controls, homozygous genotype (TT) in $6.3 \%$ of patients, and $2.5 \%$ of controls while heterozygous (CT) genotype in $32.5 \%$ of patients and $15 \%$ of controls $(P=0.011)$. Grade 1 PDUS was found in $30.6 \%$ of CC and $11.5 \%$ of CT and not found in TT genotypes. The grade 2 was found in $69.4 \%, 65.4 \%$, and only $20 \%$ of CC, CT, and TT genotypes, respectively. The grade 3 was found in $80 \%$ of TT, $23.1 \%$ of CT, and none of CC genotypes $(P<0.001)$.

Conclusion: An association between VEGF gene SNP rs3025039 and increased risk for RA among a sample of Egyptian population was noticed. VEGF gene polymorphism appears to be a potential diagnostic activity indicator and a promising therapeutic target for RA patients.
\end{abstract}

Keywords: Rheumatoid arthritis, VEGF, PCR-RFLP, Genotyping, DAS-28 ESR

\section{Background}

Rheumatoid arthritis (RA) is a chronic, systemic, and progressive inflammatory disorder primarily characterized by persistent chronic synovitis, progressive erosions, and cartilage destruction, which may cause deformed and painful joints, even resulting in loss of function [1]. The full etiology of RA remains unclear; in addition to the contributions of infectious, hormonal, and environmental factors, several lines of evidence have suggested

\footnotetext{
*Correspondence: Rehabsallam@hotmail.com

1 Department of Rheumatology and Rehabilitation, Faculty of Medicine,

Mansoura University, Mansoura, Dakhlia, Egypt

Full list of author information is available at the end of the article
}

that the disease has a genetic basis [2]. RA is characterized by infiltration of the synovial membrane in multiple joints with $\mathrm{T}$ cells, $\mathrm{B}$ cells, and monocytes. This process is preceded by activation of endothelial cells; neovascularization (growth of new blood vessels) is another hallmark of RA synovitis [1-3].

Expansion of synovial fibroblast-like and macrophagelike cells leads to a hyperplastic synovial lining layer. This expanded synovial membrane, often termed "pannus," invades the periarticular bone at the cartilage-bone junction and leads to bony erosions and cartilage degradation $[3,4]$.

Vascular endothelial growth factor (VEGF) is the most potent angiogenic factor produced by endothelial cells, 
fibroblasts, T cells, and macrophages [5, 6]. VEGF gene is located at chromosome $6 \mathrm{p} 21.3$, covering $14 \mathrm{~kb}$ in length with eight exons and seven introns. The VEGF gene has been found to be highly polymorphic and more than 30 single nucleotide polymorphisms (SNPs) have been reported [7,8]. The VEGF gene is also an independent risk factor for RA severity and correlates with multiple disease parameters, such as disease activity, joint damage, and functional disability $[3,9]$.

\section{Aim of work}

This study aimed to investigate the impact of a common genetic polymorphism in the VEGF gene on disease activity and synovial lesions in patients with RA among a sample of Egyptian population.

\section{Methods}

\section{Ethical statement}

Prior to inclusion in the study, all participants were adequately informed about the aim and the procedures of the study. The protocol was accepted by Institutional Research Board (IRB) Mansoura Faculty of Medicine in May 2016 code Number (MS/16.05.22). An informed written consent was obtained from all participants.

\section{Study population}

In this case-control study, 80 consecutive RA patients were recruited from the Rheumatology and Rehabilitation Outpatient Clinics, between July 2016 and July 2019. In addition, 80 age- and sex-matched healthy control volunteers were randomly enrolled in the study. Patients and control subjects had the same ethnicity (all were Caucasian) and were from the same geographical area. Patients were diagnosed according to the American college of Rheumatology/European league against rheumatism (ACR/EULAR) 2010 criteria [10], and all of them were conventional DMARD therapy without corticosteroid therapy. Patients with other autoimmune rheumatic diseases, overlapping arthritis, family history of autoimmune diseases, and concomitant infection and patients with age less than or equal to 18 years were excluded from the study.

All RA patients were subjected to full history taking and thorough general and systemic examination as well as musculoskeletal examinations. Visual analog scale (VAS) for pain was used to detect the level of perception of pain intensity in RA patients. A total of 28 joints including bilateral glenohumeral, elbow, wrist, metacarpophalangeal joints (MCPjs), proximal interphalangeal joints (PIPjs), and knee and ankle joints were assessed for each patient to determine tender joint count (TJC) and swollen joint count (SJC). The RA activity was assessed by disease activity score 28 (DAS-28), ESR version (based on 28 joints) [11]. Venous blood samples were withdrew from all participants through antecubital venipuncture. These samples were used for VEGF genotyping and for measurement of ESR, CRP, RF, and anti-citrullinated protein antibody levels.

Power Doppler ultrasonography (PDUS) (Siemens ACUSON P300 color Doppler, Italy) with the probe frequency of $12-18 \mathrm{MHZ}$ was used to assess the intensity of the synovial blood flow. The most affected joints of each RA patient were examined using direct contact method. A semi-quantitative scoring system to assess the flow was graded in a four-step scale [12] as follows: grade 0, being with no signal visualized, grade 1 , having one single or several vessels visualized, grade 2 , less than $50 \%$ of the region of interest having signal, and grade 3 , being more than $50 \%$ of the region of interest having signal.

\section{Genotyping of the SNP rs3025039 polymorphisms VEGF gene}

DNA was isolated from peripheral blood using Thermo Scientific whole blood genomic DNA purification Mini Kit K0781. The nucleotide sequence of VEGF gene polymorphism which was in the promoter region was amplified by polymerase chain reaction (PCR). The primers for rs3025039 were 5'-AGGGTTTCGGGAACCAGATC-3' (forward) and 5'-CTCG GTGATTTAGCAGCAAG$3^{\prime}$ (reverse). Genotypes were determined by restriction fragment length polymorphism (RFLP). The VEGF rs3025039 polymorphism was analyzed by digestion of the PCR product with restriction endonuclease NlaIII (Bio Basic Canada Inc.).

\section{Statistical analysis}

All statistical calculations were done through SPSS the version 20.0 statistic software. Continuous variables were tested for normality of distribution prior to statistical calculations. All continuous variables were normally distributed and were presented in mean $\pm \mathrm{SD}$. Categorical variables were presented in number and percentage. The comparisons were performed using independent sample Student's $t$ test for comparison between two continuous variables or one-way ANOVA test for comparison of three continuous variables. Chi-square test was used for comparison of categorical variables. Odds ratio were calculated to measure the association between an exposure (presence of alleles) and an outcome (occurrence of $\mathrm{RA}$ ). The $95 \%$ confidence interval (CI) was used to estimate precision of OR [13]. The Hardy-Weinberg equilibrium (HWE) was evaluated by the goodness-of-fit $X^{2}$ test to compare the observed genotype frequencies with the expected frequencies in controls in order to test the assumption that genotype frequencies in a population 
will remain constant from generation to generation [14]. Statistical significance was set at $P \leq 0.05$.

\section{Results}

The RA patients and controls did not differ significantly as regards age $(P=0.482)$ and sex $(P=0.079)$. The two groups were matched regarding the age and sex distribution (Table 1). Table 2 shows range, mean \pm SD of clinical findings, composite activity indices, laboratory findings, and PDUS findings.

As shown in Table 3, genotype frequencies of SNP rs3025039 of the controls fitted the HWE among

Table 1 Comparison of age and sex distribution between RA patients and controls

\begin{tabular}{lllll}
\hline & \multicolumn{2}{l}{ Student's $\boldsymbol{t}$ test } & & \\
\cline { 2 - 5 } & RA patients & Controls & $\boldsymbol{t}$ & $\boldsymbol{P}$ \\
\hline $\begin{array}{l}\text { Age (years) } \\
\text { Range }\end{array}$ & $25-66$ & $25-65$ & & \\
$\quad \begin{array}{l}\text { Mean } \pm \text { SD } \\
\text { Sex }(n, \%)\end{array}$ & $47.8 \pm 10.7$ & $46.7 \pm 11.3$ & 0.705 & 0.482 \\
$\quad$ Females & $68,85.0 \%$ & $59,73.8 \%$ & & \\
$\quad$ Males & $12,15.0 \%$ & $21,26.2 \%$ & $3.092^{*}$ & 0.079 \\
\hline
\end{tabular}

$R A$ rheumatoid arthritis, $S D$ standard deviation

${ }^{*} X^{2}$ value, chi-square test, level of significance at $P \leq 0.05$ controls $\left(\chi^{2}=2.413 ; P=0.112\right)$. The allele as well as genotype distribution of the SNP rs3025039 of VEGF gene is compared between RA patients and controls and illustrated in Table 3. T allele is present in the RA group more frequently than the control group $(22.5 \%$ vs. $10 \%$ respectively). Meanwhile, $\mathrm{C}$ allele is less frequent in the RA group than controls $(77.7 \%$ vs. $90 \%$ respectively). This difference was significant $(\mathrm{OR}=1.559,95 \% \mathrm{CI}=1.23-1.97, P=0.002)$.

Homozygous genotype (CC) was found in $61.2 \%$ of patients and $82.5 \%$ of controls. Homozygous genotype (TT) was found in $6.3 \%$ of patients and $2.5 \%$ of controls. $32.5 \%$ of patients and $15 \%$ of controls carried the heterozygous (CT) genotype respectively (Fig. 1). These differences were statistically significant $(P=0.011)$ (Table 3).

Concerning clinical findings, TJC and SJC were significantly higher in $\mathrm{T}$ allele than in $\mathrm{C}$ allele and ( $P=0.038$ and $P=0.025$, respectively). Moreover, TJC and SJC were significantly higher in TT genotype than in $\mathrm{CT}$ and $\mathrm{CC}$ genotypes being lowest in CC genotype $(P=0.020$ and $P=0.005$ respectively). As regards composite activity indices, DAS-28ESR was significantly higher in $\mathrm{T}$ allele than in $\mathrm{C}$ allele $(P=0.004)$, and it was significantly higher in TT genotype than in $\mathrm{CT}$ and $\mathrm{CC}$ genotypes being lowest in $\mathrm{CC}$ genotype $(P=0.003)$. In contrast, disease duration, morning stiffness duration,

Table 2 Clinical findings, composite indices, and laboratory findings of RA patients

\begin{tabular}{|c|c|c|}
\hline & Range & Mean \pm SD \\
\hline \multicolumn{3}{|l|}{ Clinical findings } \\
\hline Duration of RA (years) & $3-14$ & $8.3 \pm 3.2$ \\
\hline Duration of morning stiffness (minutes) & $30-240$ & $138.8 \pm 64.6$ \\
\hline Tender joint count & $7-17$ & $11.4 \pm 2.2$ \\
\hline Swollen joint count & $8-16$ & $10.0 \pm 2.0$ \\
\hline VAS pain (mm) & $28-71$ & $53.7 \pm 10.7$ \\
\hline \multicolumn{3}{|l|}{ Composite activity indices } \\
\hline DAS-28 ESR & $1.64-6.38$ & $3.89 \pm 1.4$ \\
\hline \multicolumn{3}{|l|}{ Laboratory findings } \\
\hline ESR (mm/hour) & $26.0-103.0$ & $51.4 \pm 18.7$ \\
\hline CRP $(\mathrm{mg} / \mathrm{dl})$ & $1.4-48.0$ & $24.9 \pm 13.3$ \\
\hline +ve $\operatorname{RF}(n, \%)$ & $57,71.3 \%$ & \\
\hline +ve anti-CCP $(n, \%)$ & $48,60.0 \%$ & \\
\hline \multicolumn{3}{|l|}{ PDUS findings $(n, \%)$} \\
\hline Grade 1 (one single or several vessels visualized) & $18,22.5 \%$ & \\
\hline Grade 2 (less than $50 \%$ of the region of interest having signal) & $52,65.0 \%$ & \\
\hline Grade 3 (more than $50 \%$ of the region of interest having signal) & $10,12.5 \%$ & \\
\hline
\end{tabular}

Level of significance at $P \leq 0.05$

$D A S-28$ disease activity score, ESR erythrocyte sedimentation rate, $C R P C$-reactive protein, $R F$ rheumatoid factor, anti-CCP anti-cyclic citrullinated peptide antibody, VAS visual analog scale 
Table 3 Comparison of alleles and genotyping distribution of VEGF gene SNP rs3025039 between RA patients and controls

\begin{tabular}{|c|c|c|c|c|c|c|c|c|}
\hline & \multicolumn{2}{|c|}{ RA patients } & \multicolumn{2}{|c|}{ Controls } & \multicolumn{2}{|c|}{ Chi-square test } & \multirow[b]{2}{*}{ OR, } & \multirow[b]{2}{*}{$95 \% \mathrm{Cl}$} \\
\hline & $N$ & $\%$ & $n$ & $\%$ & $x^{2}$ & $P$ & & \\
\hline HWE & & & & & 2.413 & 0.112 & & \\
\hline \multicolumn{9}{|l|}{ Alleles } \\
\hline Callele & 124 & 77.5 & 144 & 90.0 & & & & \\
\hline Tallele & 36 & 22.5 & 16 & 10.0 & 9.185 & 0.002 & 1.559 & $1.23-1.97$ \\
\hline \multicolumn{9}{|c|}{ Genotyping } \\
\hline $\mathrm{CC}$ & 49 & 61.2 & 66 & 82.5 & & & & \\
\hline $\mathrm{CT}$ & 26 & 32.5 & 12 & 15.0 & & & & \\
\hline TT & 5 & 6.3 & 2 & 2.5 & 8.957 & 0.011 & & \\
\hline
\end{tabular}

Level of significance at $P \leq 0.05$

HWE Hardy-Weinberg equilibrium, $C I$ confidence interval, $O R$ odds ratio, VEGF vascular endothelial growth factor

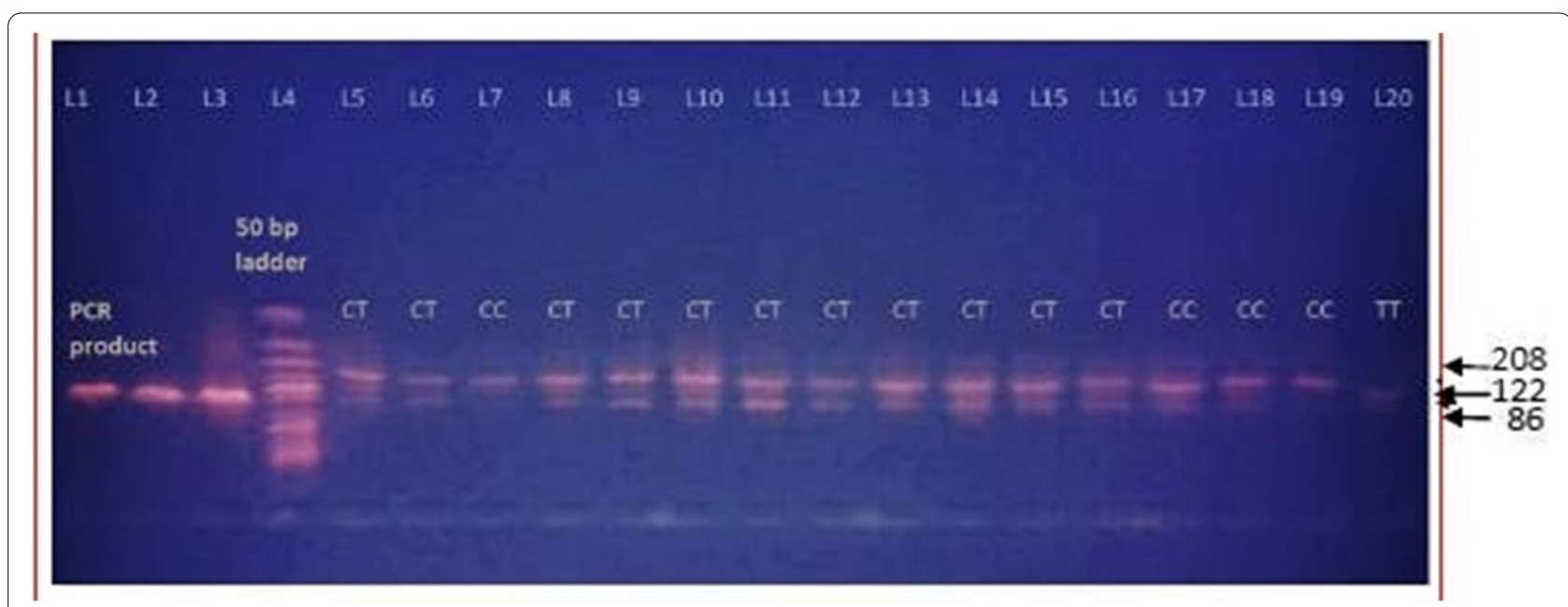

Fig. 1 Lanes 1, 2 and 3 show PCR products. Lane 4 shows a 50 bp DNA ladder; lanes 5, 6, and 8-16 show the heterozygote (CT) cut into fragments of lengths 208 and 122. Lanes 7 and 17-19 show the homozygous (CC) uncut, having a length of 208 bp. Lane 20 shows the homozygous (TT) uncut, having a length of $86 \mathrm{bp}$ (lanes are numbered in the image from left to right)

and VAS pain did not show any significant differences among RA patients' genotyping.

As regards lab findings, ESR was significantly higher in $\mathrm{T}$ allele than in $\mathrm{C}$ allele $(P<0.001)$. Additionally, it was significantly higher in TT genotype than in CT and CC genotypes being lowest in CC genotype $(P<0.001)$. However, CRP did not show any significant difference among RA. Also, the RA patients' genotyping did not differ significantly as regards $\operatorname{RF}(P=0.189)$ and antiCCP $(P=0.574)$ (Table 4).

Regarding the PDUS grading, grade 1 was found in $26.6 \%$ and $8.3 \%$ of patients with $\mathrm{C}$ allele and $\mathrm{T}$ allele respectively. The grade 2 was found in $68.5 \%$ and $52 \%$
RA patients with $\mathrm{C}$ and $\mathrm{T}$ alleles respectively. On the other hand, while $38.9 \%$ of the patients with $\mathrm{T}$ allele had grade 3 , only $4.8 \%$ of patients with $C$ allele had grade 3 . These differences were significant $(P<0.001)$. Moreover, $30.6 \%$ and $11.5 \%$ of patients with $C C$ and CT genotypes had grade 1 , respectively, while none of the patients with TT genotype had grade 1 . The grade 2 was found in $69.4 \%, 65.4 \%$, and only $20 \%$ of RA patients with $\mathrm{CC}, \mathrm{CT}$, and $\mathrm{TT}$ genotyping, respectively. In contrast, while $80 \%$ of the patients with TT genotype had grade 3 , none of patients with $C C$ genotype had grade 3 , and only $23.1 \%$ of the patients with CT genotype had grade 3 . These differences were significant $(P<0.001)$ (Tables 5 and 6). 
Table 4 Comparison of the clinical features, activity indices, and laboratory findings among the VEGF gene SNP rs3025039 in RA patients

\begin{tabular}{|c|c|c|c|c|c|}
\hline & \multirow{2}{*}{$\begin{array}{l}\text { CC } \\
\text { Mean } \pm \text { SD }\end{array}$} & \multirow{2}{*}{$\begin{array}{l}\text { CT } \\
\text { Mean } \pm \text { SD }\end{array}$} & \multirow{2}{*}{$\begin{array}{l}\text { TT } \\
\text { Mean } \pm \text { SD }\end{array}$} & \multicolumn{2}{|c|}{ ANOVA test } \\
\hline & & & & $\mathrm{F}$ & $P$ \\
\hline \multicolumn{6}{|l|}{ Clinical findings } \\
\hline Duration of RA (years) & $8.1 \pm 3.3$ & $8.4 \pm 3.0$ & $8.8 \pm 4.4$ & 0.130 & 0.878 \\
\hline $\begin{array}{l}\text { Duration of morning stiffness } \\
\text { (minutes) }\end{array}$ & $131.6 \pm 62.3$ & $146.5 \pm 64.5$ & $168.0 \pm 80.4$ & 0.998 & 0.373 \\
\hline TJC & $10.9 \pm 2.1$ & $11.8 \pm 2.1$ & $13.6 \pm 2.9$ & 4.125 & 0.020 \\
\hline SJC & $9.6 \pm 1.7$ & $10.4 \pm 2.0$ & $12.4 \pm 3.0$ & 5.719 & 0.005 \\
\hline VAS pain (mm) & $51.7 \pm 11.5$ & $56.7 \pm 9.2$ & $58.0 \pm 2.0$ & 2.357 & 0.102 \\
\hline \multicolumn{6}{|l|}{ Composite activity indices } \\
\hline DAS-28 ESR & $3.6 \pm 1.3$ & $4.2 \pm 1.4$ & $5.4 \pm 0.9$ & 6.215 & 0.003 \\
\hline \multicolumn{6}{|l|}{ Laboratory findings } \\
\hline ESR (mm/hour) & $46.5 \pm 15.3$ & $56.2 \pm 20.0$ & $75.0 \pm 20.6$ & 7.619 & $<0.001$ \\
\hline CRP (mg/dl) & $25.7 \pm 10.5$ & $28.3 \pm 13.3$ & $35.5 \pm 8.8$ & 1.867 & 0.162 \\
\hline
\end{tabular}

Level of significance at $P \leq 0.05$

VEGF vascular endothelial growth factor, CRP C-reactive protein; DAS, disease activity score, ESR erythrocyte sedimentation rate, SJC swollen joint count, TJC tender joint count, VAS visual analog scale

Table 5 Comparison of distribution of RF, anti-CCP, and PDUS grading among the VEGF gene SNP rs3025039 in RA patients

\begin{tabular}{|c|c|c|c|c|c|c|c|c|}
\hline & \multicolumn{2}{|l|}{$\mathrm{CC}$} & \multicolumn{2}{|l|}{ СT } & \multicolumn{2}{|c|}{$\mathrm{TT}$} & \multicolumn{2}{|c|}{ Chi-square test } \\
\hline & $N$ & $\%$ & $n$ & $\%$ & $n$ & $\%$ & $x^{2}$ & $P$ \\
\hline \multicolumn{9}{|l|}{ RF } \\
\hline$-v e$ & 13 & 26.5 & 10 & 38.5 & 0 & 0.0 & & \\
\hline+ ve & 36 & 73.5 & 16 & 61.5 & 5 & 100.0 & 3.332 & 0.189 \\
\hline \multicolumn{9}{|c|}{ Anti-CCP titer $(n, \%)$} \\
\hline$-v e$ & 18 & 36.7 & 11 & 42.3 & 3 & 60.0 & & \\
\hline +ve & 31 & 63.3 & 15 & 57.7 & 2 & 40.0 & 1.109 & 0.574 \\
\hline \multicolumn{9}{|c|}{ PDUS findings $(n, \%)$} \\
\hline Grade 1 & 15 & 30.6 & 3 & 11.5 & 0 & 0.0 & & \\
\hline Grade 2 & 34 & 69.4 & 17 & 65.4 & 1 & 20.0 & & \\
\hline Grade 3 & 0 & 0.0 & 6 & 23.1 & 4 & 80.0 & 32.327 & $<0.001$ \\
\hline
\end{tabular}

Level of significance at $P \leq 0.05$

VEGF vascular endothelial growth factor, anti-CCP anti-cyclic citrullinated peptide, $P D U S$ power Doppler ultrasound, $R F$ rheumatoid factor

\section{Discussion}

Rheumatoid arthritis is a chronic multisystem inflammatory disease characterized mainly by inflammation of the synovial joints. The inflammation in the RA joint is associated with inflammatory cell infiltration and synovial lining hyper-proliferation as well as excessive pro-inflammatory mediator's production [15].

Having a first-degree relative with high familial incidence in RA is one of the strongest risk factors for developing RA. This highlights the important role of genetic studies and GWAS in early RA detection [16].

Vascular endothelial growth factor is one of the most potent factors in RA development that seems to be responsible for the typical hypertrophied synovium (pannus), edema, swelling, and chondrolytic and osteolytic reactions and is expressed in synovial fibroblasts, fibroblasts close to microvessels, vascular smooth muscle, and macrophages, but not in endothelial cells [17].

Serum VEGF levels are upregulated in RA patients. In addition, synovial fluid or synovial cells from RA patients also contain high levels of VEGF, and VEGF levels are positively correlated with disease activity and joint destruction in RA [18].

Given the potential link between VEGF and autoimmune or inflammatory diseases, VEGF polymorphisms, which may influence VEGF expression, have been studied 
Table 6 Comparison of distribution of RF, anti-CCP, and PDUS grading between T allele and C allele of the VEGF gene SNP rs3025039 in RA patients

\begin{tabular}{|c|c|c|c|c|c|c|}
\hline & \multicolumn{2}{|c|}{ C allele } & \multicolumn{2}{|c|}{ T allele } & \multicolumn{2}{|c|}{ Chi-square test } \\
\hline & $n$ & $\%$ & $\bar{N}$ & $\%$ & $x^{2}$ & $P$ \\
\hline \multicolumn{7}{|l|}{ RF } \\
\hline$-v e$ & 32 & 25.8 & 14 & 38.9 & & \\
\hline+ ve & 92 & 74.2 & 22 & 61.1 & 2.331 & 0.127 \\
\hline \multicolumn{7}{|c|}{ Anti-CCP titer $(n, \%)$} \\
\hline$-v e$ & 51 & 41.1 & 13 & 36.1 & & \\
\hline+ ve & 73 & 58.9 & 23 & 63.9 & 0.293 & 0.588 \\
\hline \multicolumn{7}{|c|}{ PDUS findings ( $n, \%)$} \\
\hline Grade 1 & 33 & 26.6 & 3 & 8.3 & & \\
\hline Grade 2 & 85 & 68.5 & 19 & 52.8 & & \\
\hline Grade 3 & 6 & 4.8 & 14 & 38.9 & 31.059 & $<0.001$ \\
\hline
\end{tabular}

Level of significance at $P \leq 0.05$

VEGF vascular endothelial growth factor, anti-CCP anti-cyclic citrullinated peptide, $P D U S$ power Doppler ultrasound, $R F$ rheumatoid factor

as potential causes of autoimmune or inflammatory diseases [19].

This attracts the attention to study the effect of its gene SNPs in RA incidence and pathogenesis. Our study was designed to investigate the impact of a common genetic polymorphism in the VEGF gene on disease activity and synovial lesions in patients with RA.

In the present study as regards SNP rs3025039, the $\mathrm{T}$ allele frequencies were higher in patients compared to the control group ( $22.5 \%$ vs. $10 \%$ respectively), making it a risky allele. On the other hand, the $\mathrm{C}$ allele frequencies were lower in patients compared to the control group $(77.7 \%$ vs. $90 \%$ respectively), making it a protective allele $(\mathrm{OR}=1.559,95 \% \mathrm{CI}=1.23-1.97, P=0.002)$. Regarding TT and CC genotypes in this study, there was a statistical difference in their frequencies in patients (6.3\% and 61.2\%) compared to the control group (2.5\% and $82.5 \%$. respectively), making the TT genotype a risky genotype while the $\mathrm{CC}$ genotype seemed to be protective $(p=0.011)$.

The presented results come in agreement with Han et al. [20] who examined rs3025039 SNP of VEGF gene using PCR-RFLP restriction fragment length polymorphism in Korean RA patients and detected significant association between $\mathrm{T}$ allele and increased susceptibility to RA.

The results were also in harmony with Lv et al. [21] research in China which was conducted on eight nucleotide polymorphisms including rs3025039 of VEGF gene analyzed using Sequenom MassArray platform and found decreased CC genotype in patients with RA compared to controls.

A previous meta-analysis [19] reported no association between the rs3025039 of VEGF gene polymorphisms and the development of RA. This finding may be explained by methodological differences, significant heterogeneity among these studies, and different clinical and environmental characteristics.

In our study, there is a significant association between TT genotype and high ESR in RA patients, while other laboratory investigations (CRP, RF, anti CCP ab) did not show any significant difference between genotypes.

In clinical disease activity evaluation by DAS-28 ESR, there is a significant association between vascular endothelial growth factor TT genotype and high DAS-28 grading as well as CC genotype and low DAS-28 grading.

The presented result comes in agreement with an earlier study [3] that demonstrated significantly high ESR levels in patients with RA. Also, they found significant association between the different genotypes of VEGF rs833070 in RA patients and DAS-28, although we did not study the same SNP.

In RA, MSUS can be now considered a complement to physical examination. This method evaluates synovitis through GS and power Doppler, and it is also able to identify bone erosions. Current data account for good correlation of MSUS with classical measures of clinical activity; in some instances, MSUS appears to perform even better. Diagnosis of subclinical synovitis by MSUS might help the physician in RA management [22].

Radiological evaluation of rheumatoid patients in the study by PDUS revealed that there is a significant association between VEGF gene polymorphisms and high PDUS grading.

Our results are in harmony with Chinese study of [3] that detected significant association between VEGF gene polymorphisms and PDUS, although we did not study the same SNP. Despite our interesting and novel findings 
in the present study, some limitations of our study should be stated. First, this was a hospital-based case-control study, so the subjects are not fully representative of the general population. Moreover, our study was performed in a small population, and further studies in a big population are needed to confirm our findings.

\section{Limitations}

Our study was performed on a relatively small population and from one geographical region, so our results should be confirmed on a larger sample size and on different populations for better understanding of the molecular genetics of angiogenesis as well as inflammation in RA.

\section{Conclusions}

This study reveals a trend of an association between VEGF gene SNP rs3025039 and increased risk for RA among a sample of Egyptian population. Notably, VEGF gene SNP rs3025039 in RA patients is significantly associated with high disease activity. Moreover, TT genotype may be a potential genetic susceptibility factor for RA and that $\mathrm{CC}$ genotype may be a potential genetic protective factor for RA. Thus, VEGF gene polymorphism appears to be a potential diagnostic activity indicator and a promising therapeutic target for RA patients.

\begin{abstract}
Abbreviations
VEGF: Vascular endothelial growth factor; RA: Rheumatoid arthritis; DAS-28: Disease activity score 28; PCR: Polymerase chain reaction; PDUS: Power Doppler ultrasonography; IRB: Institutional Research Board; ACR/EULAR: American college of Rheumatology/European league against rheumatism; VAS: Visual analog scale; MCPs: Metacarpophalangeal joints; PIPJs: Proximal interphalangeal joints; TJC: Tender joint count; SJC: Swollen joint count; Cl: Confidence interval; HWE: The Hardy-Weinberg equilibrium.
\end{abstract}

\section{Acknowledgements}

Not applicable.

\section{Authors' contributions}

RS and ME contributed in writing the manuscript, doing the statistics, and revising the clinical work; BS did the clinical part of the study. BE did the study design and revised the research work. All authors read and approved the final manuscript.

\section{Funding}

Nil (author's own fund).

\section{Availability of data and materials}

The datasets used and/or analyzed during the current study are available from the corresponding author on reasonable request.

\section{Declarations}

Ethics approval and consent to participate

Patients were informed about the nature of the study, and a written consent was taken from the participants who agreed to share. The study was approved by the institutional research board of Mansoura Faculty of Medicine (IRB) in May 2016, code Number (MS/16.05.22).
Consent for publication

Not applicable.

\section{Competing interests}

The authors declare that they have no competing interests.

\section{Author details}

${ }^{1}$ Department of Rheumatology and Rehabilitation, Faculty of Medicine, Mansoura University, Mansoura, Dakhlia, Egypt. ${ }^{2}$ Department of Clinical Pathology, Faculty of Medicine, Mansoura University, Mansoura, Dakhlia, Egypt.

Received: 3 September 2021 Accepted: 6 November 2021

Published online: 20 December 2021

\section{References}

1. Wang Ch, Yao H, Chen Ln, Jia Jf, Wang L, Dai Jy, Zheng Zh, Chen Zn, Zhu $P(2012)$ CD147 induces angiogenesis through a vascular endothelial growth factor and hypoxia-inducible transcription factor 1a-mediated pathway in rheumatoid arthritis. Arthritis Rheum 64:1818-1827

2. Zhang Y, Qiu H, Zhang H, Wang L, Zhuang C, Liu R (2013) Vascular endothelial growth factor A (VEGFA) polymorphisms in Chinese patients with rheumatoid arthritis. Scand J Rheumatol 42:344-348

3. Yi J-P, Wu Y-Z, Yu N, Yu Z-W, Xie F-Y, Yuan Q (2016) VEGF gene polymorphisms affect serum protein levels and alter disease activity and synovial lesions in rheumatoid arthritis. Med Sci Monit 22:316

4. Aletaha D, Smolen JS (2018) Diagnosis and management of rheumatoid arthritis: a review. Jama 320:1360-1372

5. Kim H-R, Kim K-W, Kim B-M, Cho M-L, Lee S-H (2015) The effect of vascular endothelial growth factor on osteoclastogenesis in rheumatoid arthritis. PLoS One 10:e0124909

6. Elshabrawy HA, Chen Z, Volin MV et al (2015) The pathogenic role of angiogenesis in rheumatoid arthritis. Angiogenesis 18:433-448

7. Wei N, Chen Z, Xue Z, Zhu Y (2015) Polymorphism of VEGF gene in susceptibility to chronic immune-mediated inflammatory diseases: a meta-analysis. Rheumatol Int 35:1351-1360

8. Che N, Li Y, Liu S et al (2015) Investigation on association between five common polymorphisms in vascular endothelial growth factor and prototypes of autoimmune diseases. Immunobiology 220:722-733

9. Jin-Ping Y, Yu-Zhang W, Nan Y (2016) VEGF \& disease activity and synovial lesions in RA. Med Sci Monit 22:316-313

10. Aletaha D, Neogi T, Silman AJ, Funovits J, Felson DT, Bingham CO III, Birnbaum NS, Burmester GR, Bykerk VP, Cohen MD (2010) 2010 rheumatoid arthritis classification criteria: an American College of Rheumatology/ European League Against Rheumatism collaborative initiative. Arthritis Rheum 62:2569-2581

11. Prevoo M, Van'T Hof MA, Kuper H, Van Leeuwen M, Van De Putte L, Van Riel P (1995) Modified disease activity scores that include twenty-eightjoint counts development and validation in a prospective longitudinal study of patients with rheumatoid arthritis. Arthritis Rheum 38:44-48

12. Szkudlarek M, Court-Payen M, Jacobsen S, Klarlund M, Thomsen HS, Østergaard M (2003) Interobserver agreement in ultrasonography of the finger and toe joints in rheumatoid arthritis. Arthritis Rheum 48(4):955-962

13. Marie A, Krousel-Wood MA, Chambers RB, Muntner P (2007) Clinicians' guide to statistics for medical practice and research: part II. Ochsner J 7(1):3-7

14. Namipashaki A, Razaghi-Moghadam Z, Ansari-Pour N (2015) The essentiality of reporting Hardy-Weinberg equilibrium calculations in populationbased genetic association studies. Cell J (Yakhteh) 17:187

15. Araki Y, Mimura T (2016) The mechanisms underlying chronic inflammation in rheumatoid arthritis from the perspective of the epigenetic landscape. J Immunol Res 2016. https://doi.org/10.1155/2016/6290682

16. Frisell T, Hellgren K, Alfredsson L, Raychaudhuri S, Klareskog L, Askling J (2016) Familial aggregation of arthritis-related diseases in seropositive and seronegative rheumatoid arthritis: a register-based case-control study in Sweden. Ann Rheum Dis 75:183-189

17. Llorián-Salvador M, González-Rodríguez S (2018) Painful Understanding of VEGF. Front Pharmacol 9:1267 
18. Ding LL, Li X, Lei YM, Xia LP, Lu J, Shen H (2020) Effect of interleukin-34 on secretion of angiogenesis cytokines by peripheral blood mononuclear cells of rheumatoid arthritis. Immunol Invest 49:81-87

19. Lee YH, Bae S-C (2018) Correlation between circulating VEGF levels and disease activity in rheumatoid arthritis: a meta-analysis. Z Rheumatol 77:240-248

20. Han SW, Kim GW, Seo JS, Kim SJ, Sa KH, Park JY, Lee J, Kim SY, Goronzy JJ, Weyand CM (2004) VEGF gene polymorphisms and susceptibility to rheumatoid arthritis. Rheumatology 43:1173-1177

21. Lv H-z, Lin T, Xia L-p, Shen H, Zhu X-y, Zhang J-t, Xiao W-g, Lu J (2011) Vascular endothelial growth factor gene polymorphisms and rheumatoid arthritis. J Invest Med 59:593-598
22. do Prado AD, Staub HL, Bisi MC, da Silveira IG, Mendonça JA, PolidoPereira J, Fonseca JE (2018) Ultrasound and its clinical use in rheumatoid arthritis: where do we stand? Adv Rheumatol 58:19

\section{Publisher's Note}

Springer Nature remains neutral with regard to jurisdictional claims in published maps and institutional affiliations.

\section{Submit your manuscript to a SpringerOpen ${ }^{\circ}$ journal and benefit from:}

- Convenient online submission

- Rigorous peer review

- Open access: articles freely available online

- High visibility within the field

- Retaining the copyright to your article

Submit your next manuscript at $\boldsymbol{\nabla}$ springeropen.com 